\title{
The effects of catechin rich teas and caffeine on energy expenditure and fat oxidation: a meta-analysis
}

\author{
R. Hursel ${ }^{1}$, W. Viechtbauer ${ }^{2}$, A. G. Dulloo ${ }^{3}$, A. Tremblay ${ }^{4}$, L. Tappy ${ }^{5}$, W. Rumpler ${ }^{6}$ and \\ M. S. Westerterp-Plantenga ${ }^{1}$
}

\begin{abstract}
${ }^{1}$ Department of Human Biology, Nutrition and
Toxicology Research Institute Maastricht (NUTRIM), Maastricht University, Maastricht,

The Netherlands; '2Department of

Methodology and Statistics, Maastricht

University, Maastricht, The Netherlands;

${ }^{3}$ Department of Medicine/Physiology,

University of Fribourg, Fribourg, Switzerland;

${ }^{4}$ Division of Kinesiology, Laval University,

Quebec, Canada; ${ }^{5}$ Department of Physiology,

Lausanne University, Lausanne, Switzerland;

${ }^{6}$ Beltsville Human Nutrition Research Center,

Beltsville, MD, USA
\end{abstract}

Address for correspondence: R Hursel,

Department of Human Biology, Maastricht

University, PO Box 616, 6200 MD Maastricht,

The Netherlands. E-mail:

rick.hursel@hb.unimaas.nl

\begin{abstract}
Summary
Different outcomes of the effect of catechin-caffeine mixtures and caffeine-only supplementation on energy expenditure and fat oxidation have been reported in short-term studies. Therefore, a meta-analysis was conducted to elucidate whether catechin-caffeine mixtures and caffeine-only supplementation indeed increase thermogenesis and fat oxidation. First, English-language studies measuring daily energy expenditure and fat oxidation by means of respiration chambers after catechin-caffeine mixtures and caffeine-only supplementation were identified through PubMed. Six articles encompassing a total of 18 different conditions fitted the inclusion criteria. Second, results were aggregated using random/mixed-effects models and expressed in terms of the mean difference in $24 \mathrm{~h}$ energy expenditure and fat oxidation between the treatment and placebo conditions. Finally, the influence of moderators such as BMI and dosage on the results was examined as well. The catechin-caffeine mixtures and caffeine-only supplementation increased energy expenditure significantly over $24 \mathrm{~h}(428.0 \mathrm{~kJ}(4.7 \%) ; P<0.001$ and $429.1 \mathrm{~kJ}(4.8 \%) ; P<0.001$, respectively). However, $24 \mathrm{~h}$ fat oxidation was only increased by catechin-caffeine mixtures (12.2 g (16.0\%); $P<0.02$ and $9.5 \mathrm{~g}(12.4 \%) ; P=0.11$, respectively). A doseresponse effect on $24 \mathrm{~h}$ energy expenditure and fat oxidation occurred with a mean increase of $0.53 \mathrm{~kJ} \mathrm{mg}^{-1}(P<0.01)$ and $0.02 \mathrm{~g} \mathrm{mg}^{-1}(P<0.05)$ for catechin-caffeine mixtures and $0.44 \mathrm{~kJ} \mathrm{mg}^{-1} \quad(P<0.001)$ and $0.01 \mathrm{~g} \mathrm{mg}^{-1}$ $(P<0.05)$ for caffeine-only. In conclusion, catechin-caffeine mixtures or a caffeine-only supplementation stimulates daily energy expenditure dosedependently by $0.4-0.5 \mathrm{~kJ} \mathrm{mg}^{-1}$ administered. Compared with placebo, daily fat-oxidation was only significantly increased after catechin-caffeine mixtures ingestion.
\end{abstract}

Keywords: Caffeine, catechins, green tea, oolong tea.

\section{Introduction}

Tea is the most widely consumed beverage next to water in the world. People in Asia have been aware of the beneficial effects of green tea on health for hundreds of years (1), but it is only recently that green tea and oolong tea have been gaining interest in the westernized world, where mainly black tea is drunk. Both green tea and black tea are made from the fresh leaves of Camellia sinensis, but they differ in the way that the leaves are processed. In particular, green tea is processed rapidly by means of steam to prevent fermentation. Black tea is made from the same plant as green tea but the leaves endure an extra enzymatic oxidation step during the processing (1). The polyphenols in 
green tea and oolong tea such as epigallocatechin gallate (EGCG), epigallocatechin (EGC), epicatechin gallate (ECG) and epicatechin (EC), which are responsible for its beneficial effects (such as the anti-oxidant potential and anti-mutagenic capacity), are converted into thearubigins and theaflavins in black tea (2). Although black tea still can improve one's health, the conversion attenuates the effects reported after intake of green tea and oolong tea (3-5).

According to traditional Chinese belief, tea seems to be effective in the control of body weight. Since the 1990s, green tea and oolong tea are also viewed in the westernized world as natural herbs that can enhance energy expenditure and fat oxidation by activating the sympathoadrenal system and thereby inducing weight loss $(6,7)$. Several longterm studies have been conducted to examine the effects of catechin-caffeine mixtures on weight loss (8-16) and on weight maintenance following weight loss $(17,18)$. The mixed results from these studies were recently summarized in a meta-analysis showing that catechin-caffeine mixtures have a positive effect on weight loss and on weight maintenance (8). Although the evidence was limited, habitual caffeine intake and ethnicity were found to be potential moderators of these effects. A difference in genetic predisposition of subjects, probably due to multiple variants of the catechol O-methyltransferase (COMT) polymorphism, might explain the discrepancy in the outcome between studies. Furthermore, different doses of catechin-caffeine mixtures did not appear to yield significantly different effects (19).

Moreover, the stimulatory effects of a catechin-caffeine mixture on energy expenditure cannot be completely attributed to its caffeine content because the thermogenic effect of a catechin-caffeine mixture is greater than that of an equivalent amount of caffeine (20). However, the evidence remains mixed: some $24 \mathrm{~h}$ studies measuring energy expenditure and fat oxidation by means of respiration chambers showed significant increases in energy expenditure and/or fat oxidation $(20,21)$, but other more acute studies, lasting over a few hours, did not (22-24). Similar to the long-term studies, the presence of responders and non-responders may have led to mixed results, again suggesting a possible role for the genotype.

The aim of the present study was to conduct a systematic review and meta-analysis of the available short-term studies that have examined the effects of catechin-caffeine mixtures and caffeine-only supplementation on $24 \mathrm{~h}$ energy expenditure and fat oxidation, in order to establish whether catechin-caffeine mixtures and caffeine-only supplementation contribute to thermogenesis. Possible moderators, namely the body mass index (BMI) of the subjects and the catechin/caffeine dosage, are included in the meta-analysis, to investigate whether they have any impact on overall energy expenditure and fat oxidation and the effects of caffeine-only or catechincaffeine mixtures.

\section{Methods}

\section{Identification of relevant studies}

PubMed was searched for English-language studies that reported the short-term effects from catechin-caffeine mixtures and caffeine-only supplementation on energy expenditure and fat oxidation. The databases were searched up to January 2010 with the following keywords: green tea, oolong tea, caffeine, energy expenditure, thermogenesis, fat oxidation, catechins, epigallocatechin gallate or EGCG. References from the retrieved articles were examined to identify possible additional articles.

\section{Inclusion and exclusion criteria}

A study was valid for inclusion in the review if: (i) the study's participants were randomly assigned to conditions or treatment orders (in case of a within-subjects design); (ii) the results allowed a direct comparison of the effects of catechin-caffeine mixtures or caffeine-only supplementation (either in the form of catechin-caffeine mixtures or caffeine-only supplementation vs. no treatment or high- vs. low-dosage) on energy expenditure and/or fat oxidation; (iii) subjects were kept blind to the condition assigned; (iv) the study lasted for at least $23 \mathrm{~h}$ and (v) had to be conducted in a respiration chamber. The caffeine-only or catechin-caffeine mixture could either be administered as a regular beverage or as capsules.

\section{Data abstraction}

Various characteristics were extracted from the original reports using a standardized data extraction form. We recorded the study's author(s), year of publication, the duration of the measurement (in hours), and the age range, mean BMI, gender, and mean regular caffeine intake (in $\mathrm{mg} \mathrm{d}^{-1}$ ) of the participants in the study (Table 1). Moreover, for each condition, we recorded the number of participants included from each trial, the dosage of total catechins, EGCG and caffeine administered (in $\mathrm{mg} \mathrm{d}^{-1}$ ), the mean energy expenditure (in $\mathrm{kJ} \mathrm{d}^{-1}$ ) and fat oxidation (in $\mathrm{g} \mathrm{d}^{-1}$ ), and the corresponding standard errors of these means. Finally, we computed the difference in the mean energy expenditure and fat oxidation after catechincaffeine mixtures or caffeine-only supplementation when compared with placebos. A positive value for this effect size measure therefore indicates higher energy expenditure on average after treatment and therefore a stimulatory effect of catechin-caffeine mixtures or caffeine-only on thermogenesis. 


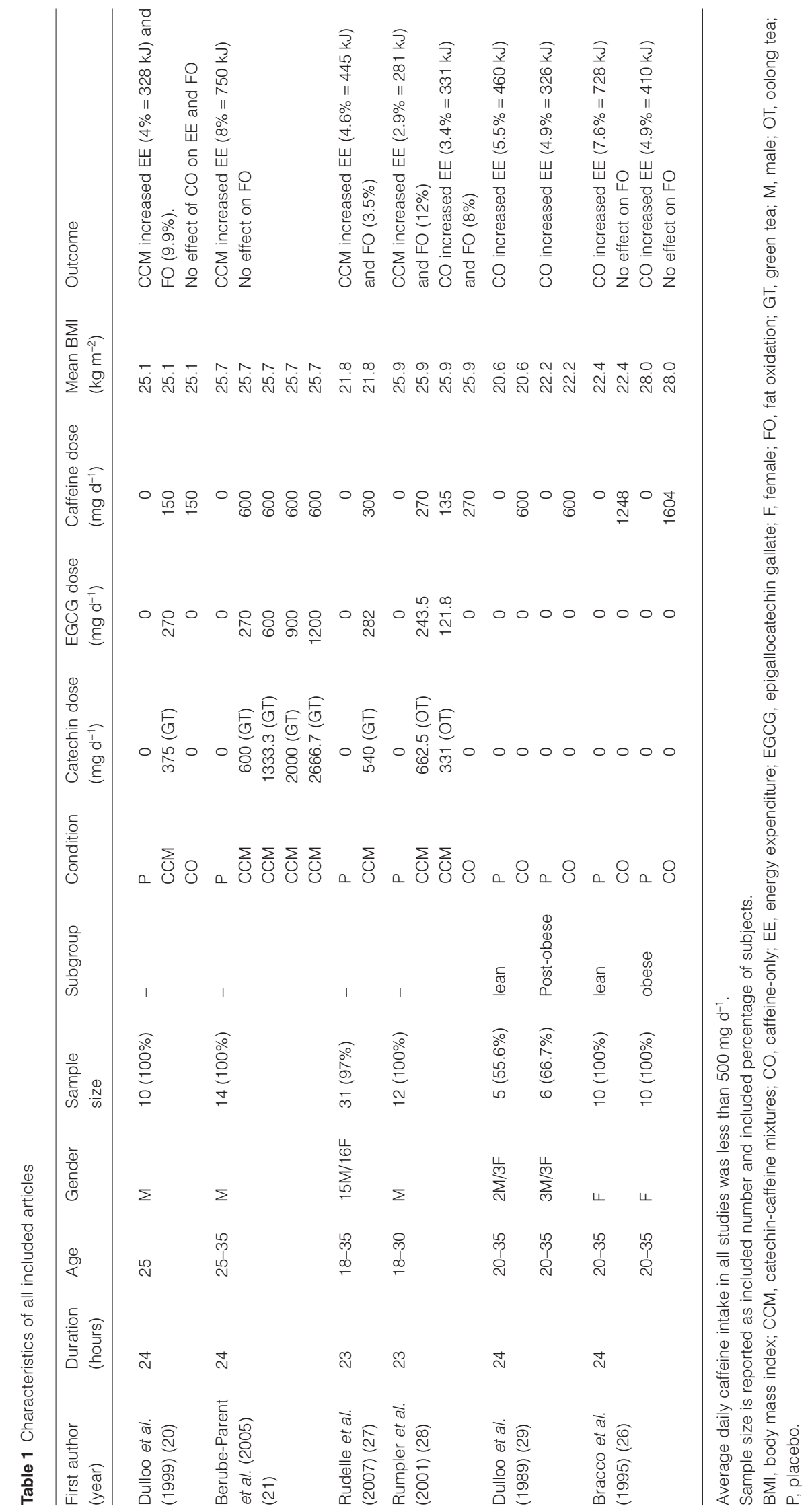




\section{Statistical analysis}

We used mixed-effects meta-regression models to estimate the mean energy expenditure and fat oxidation when only receiving placebos and the additive effects of either catechin-caffeine mixtures or caffeine-only supplementation on the mean energy expenditure and fat oxidation when compared with placebos. Because the included studies all used cross-over designs (see below), an armbased meta-analysis model was used for this purpose, allowing the estimated mean outcome (either energy expenditure or fat oxidation) for the same subjects in different conditions (study arms) to be correlated and using dummy variables to code the three different conditions (i.e. placebo, catechin-caffeine mixture or caffeine-only supplementation). We also estimated the change in the mean energy expenditure and fat oxidation for a one-unit increase in the mean BMI of the subjects (by including mean BMI as an additional variable in the model) and for each $\mathrm{mg} \mathrm{d}^{-1}$ increase in the catechin and caffeine dosage administered (by replacing the dummy variables with the variables that indicate the actual catechin and caffeine dosages administered in a particular condition).

The models were fitted using restricted maximumlikelihood estimation (25). We report the estimated mean energy expenditure and fat oxidation under placebos $\left(\hat{\beta}_{0}\right)$ and the effects of catechin-caffeine mixtures $\left(\hat{\beta}_{G}\right)$ and caffeine-only supplementation $\left(\hat{\beta}_{C}\right)$ on the mean energy expenditure and fat oxidation, and the estimated amount of heterogeneity in these effects $\left(\hat{\tau}^{2}\right)$. Corresponding $95 \%$ confidence intervals (CIs) are given for all of these statistics. We also provide the results from likelihood-ratio tests for heterogeneity. To examine whether the conclusions regarding the effects of catechin-caffeine mixtures and caffeineonly supplementation hinge on the results from a single study, sensitivity analyses were conducted for both outcomes by repeating the analyses while removing each study in turn. For the models involving BMI and the catechin and caffeine dosages, we report the estimated model coefficients with corresponding $95 \%$ CIs.

\section{Results}

Thirty-nine potentially relevant studies were found initially. From these, 12 review articles were excluded immediately, as these contributed no additional data besides the original studies, which were already included. Another 10 studies were excluded on the basis of title and abstract, as these were studies conducted with animals (seven studies) or specifically focused on the effects of catechin-caffeine mixtures or caffeine-only supplementation in combination with strenuous exercise (three studies). Of the remaining 17 studies, an additional set of 11 studies had to be excluded either because measurements lasted less than $23 \mathrm{~h}$ or

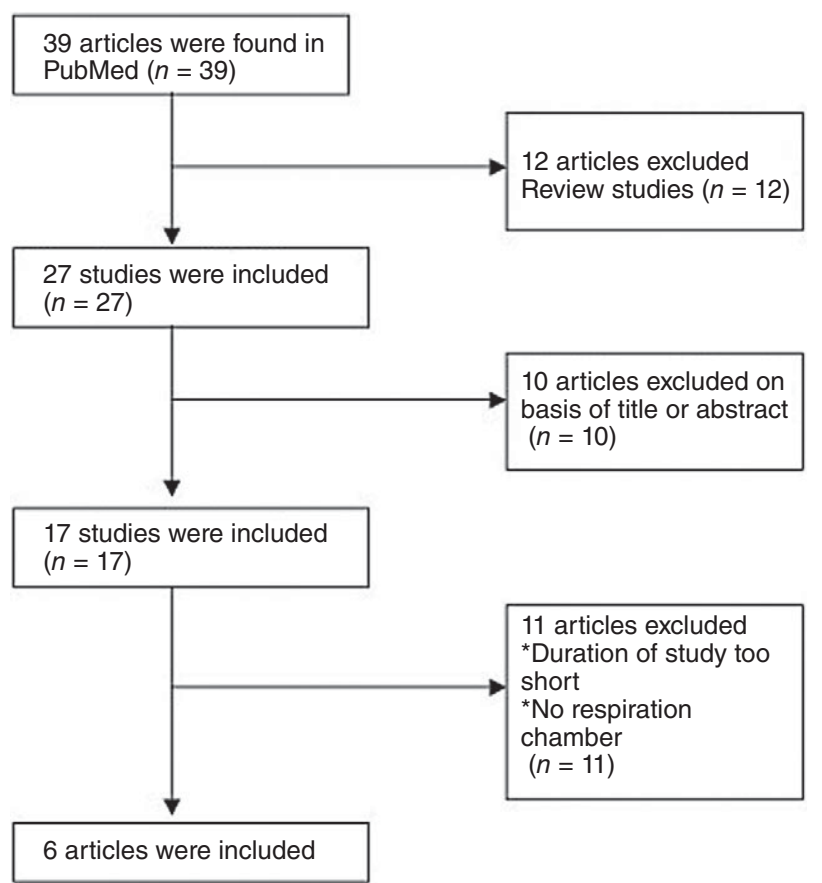

Figure 1 Process of study selection.

because they were not performed in a respiration chamber. Among the remaining studies, lack of randomization or blinding did not occur. Therefore, six articles fulfilled the inclusion criteria (20,21,26-29). Fig. 1 shows the process of study selection.

The selected articles all had comparable cross-over designs: in each study, subjects participated in all conditions in random order with at least $5 \mathrm{~d}$ in-between as wash-out period. Subjects stayed in a respiration chamber for either 23 or $24 \mathrm{~h}$ and received an intervention or placebo together with their meals. In all studies, subjects were randomly assigned to two or more conditions, and a true placebo group was used.

Almost every article reported the relevant information about the moderators, for instance as an important inclusion criterion. All studies provided information about the mean energy expenditure and fat oxidation except one, which only reported the mean energy expenditure of the subjects. A total of 18 different conditions were examined in the studies (6 placebo, 8 catechin-caffeine mixtures and 4 caffeine-only conditions).

Because several studies had a cross-over design that measured energy expenditure and/or fat oxidation under more than two conditions (either because the effects of an catechin-caffeine mixture and caffeine-only supplementation or because the effects of different dosages were compared in the same study), it was possible to calculate more than one effect size estimate for these studies. In addition, 


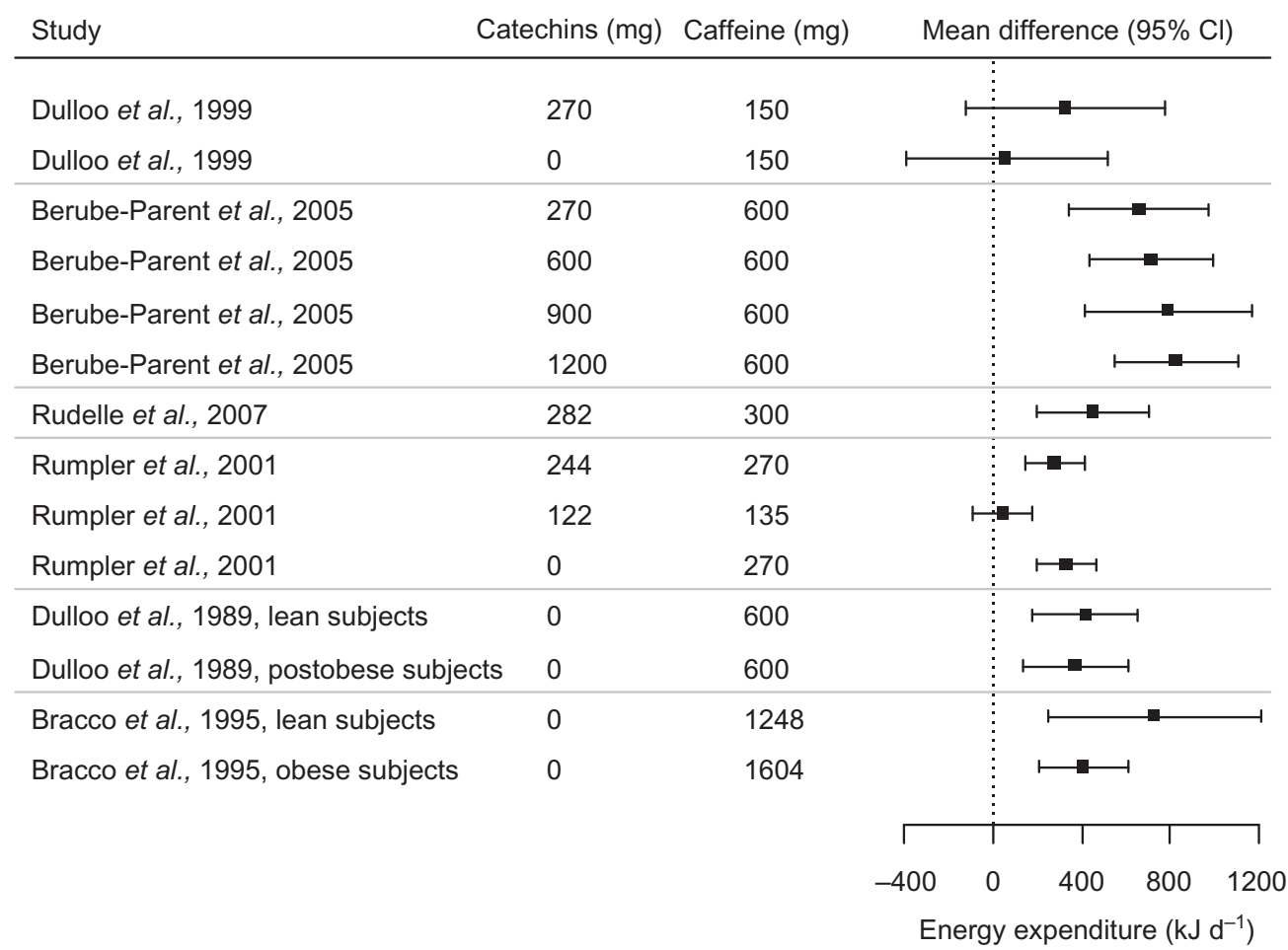

Figure 2 Plot of the mean differences (green/oolong tea or caffeine condition vs. placebo condition) with 95\% confidence intervals (Cl) for energy expenditure.

two studies reported the results separately for two subgroups of participants ('lean' vs. 'post-obese' in the first, and 'lean' vs. 'obese' subjects in the second study). Therefore, a total of 14 effect size estimates could be extracted from the six studies for energy expenditure and 12 estimates for fat oxidation. Figs 2 and 3 show a plot of the individual effect size estimates with corresponding 95\% CIs for energy expenditure and fat oxidation.

The mean energy expenditure in placebo conditions was estimated to be $\hat{\beta}_{0}=9020.3 \mathrm{~kJ} \mathrm{~d}^{-1}$ (95\% CI: 8161.0 to 9879.6). A significant positive effect on energy expenditure was found both for catechin-caffeine mixtures $\left(\hat{\beta}_{G}=428.0 \mathrm{~kJ} \mathrm{~d}^{-1}, 95 \%\right.$ CI: 252.7 to $\left.603.4 ; P<0.001\right)$ and caffeine-only supplementation $\left(\hat{\beta}_{C}=429.1 \mathrm{~kJ} \mathrm{~d}^{-1}\right.$, 95\% CI: 260.7 to $597.5 ; P<0.001)$. Therefore, it is estimated that subjects receiving catechin-caffeine mixtures and caffeine-only increase energy expenditure on average by $4.7 \%$ and $4.8 \%$, respectively. Removal of any individual study from the meta-analysis did not alter this conclusion, with effects for catechin-caffeine mixtures ranging from 296 to $601 \mathrm{~kJ} \mathrm{~d}^{-1}$ (all $P<0.002$ ) and effects for caffeineonly supplementation ranging from 398 to $468 \mathrm{~kJ} \mathrm{~d}^{-1}$ (all $P<0.001)$. However, the results were clearly heterogeneous $\left(\hat{\tau}^{2}=28069.5 ; 95 \%\right.$ CI: 6513.6 to 117096.3 ; likelihood-ratio test for heterogeneity: $\chi^{2}=23.28$, $P<0.001)$. For a one-point increase in mean BMI of the subjects, the mean energy expenditure was estimated to increase by a $344.1 \mathrm{~kJ} \mathrm{~d}^{-1}$ points (95\% CI: 75.2 to 613.0; $P<0.02)$. Finally, a clear dose-response relationship was found for both catechins and caffeine: A $1 \mathrm{mg}$ increase in the catechins dosage was estimated to yield a 0.53 -point increase in mean energy expenditure (95\% CI: 0.20 to $0.86 ; P<0.002)$, while for caffeine, mean energy expenditure was estimated to increase by 0.44 points $(95 \% \mathrm{CI}$ : 0.23 to $0.65 ; P<0.001)$ per $\mathrm{mg}$.

Mean fat oxidation under placebo conditions was estimated at $\hat{\beta}_{0}=76.4 \mathrm{~g} \mathrm{~d}^{-1}$ (95\% CI: 60.5 to 92.3 ). Treatments with catechin-caffeine mixtures yielded a significant increase of on average $\hat{\beta}_{G}=12.2 \mathrm{~g}$ of fat oxidized $(95 \% \mathrm{CI}$ : 1.7 to $22.8 ; P<0.02)$, i.e. an increase of $16.0 \%$. While caffeine-only supplementation was estimated to yield a mean increase of $\hat{\beta}_{C}=9.5 \mathrm{~g}$ of fat oxidized (95\% CI: -2.1 to 21.0$)$ or $12.4 \%$, the effect was not significant $(P=0.11)$. Removal of each study in turn yielded effects of catechincaffeine mixtures from 8.6 to $15.7 \mathrm{~g} \mathrm{~d}^{-1}$ (all $P<0.05$, except for one $P=0.13$ ) and effects of caffeine-only supplementation from 7.0 to $11.6 \mathrm{~g} \mathrm{~d}^{-1}$ (all $P>0.05$, except for one $P=0.04)$. Again, the results were heterogeneous $\left(\hat{\tau}^{2}=142.7\right.$; $95 \%$ CI: 43.7 to 558.6 ; likelihood-ratio test for heterogeneity: $\left.\chi^{2}=63.61, P<0.001\right)$. The mean BMI of the subjects had no significant influence on the mean fat oxidation $(P=0.58)$. However, significant dose-response relationships were again found for both catechins $(0.02-$ point increase for each $1 \mathrm{mg}$ increase; 95\% CI: 0.01 to 


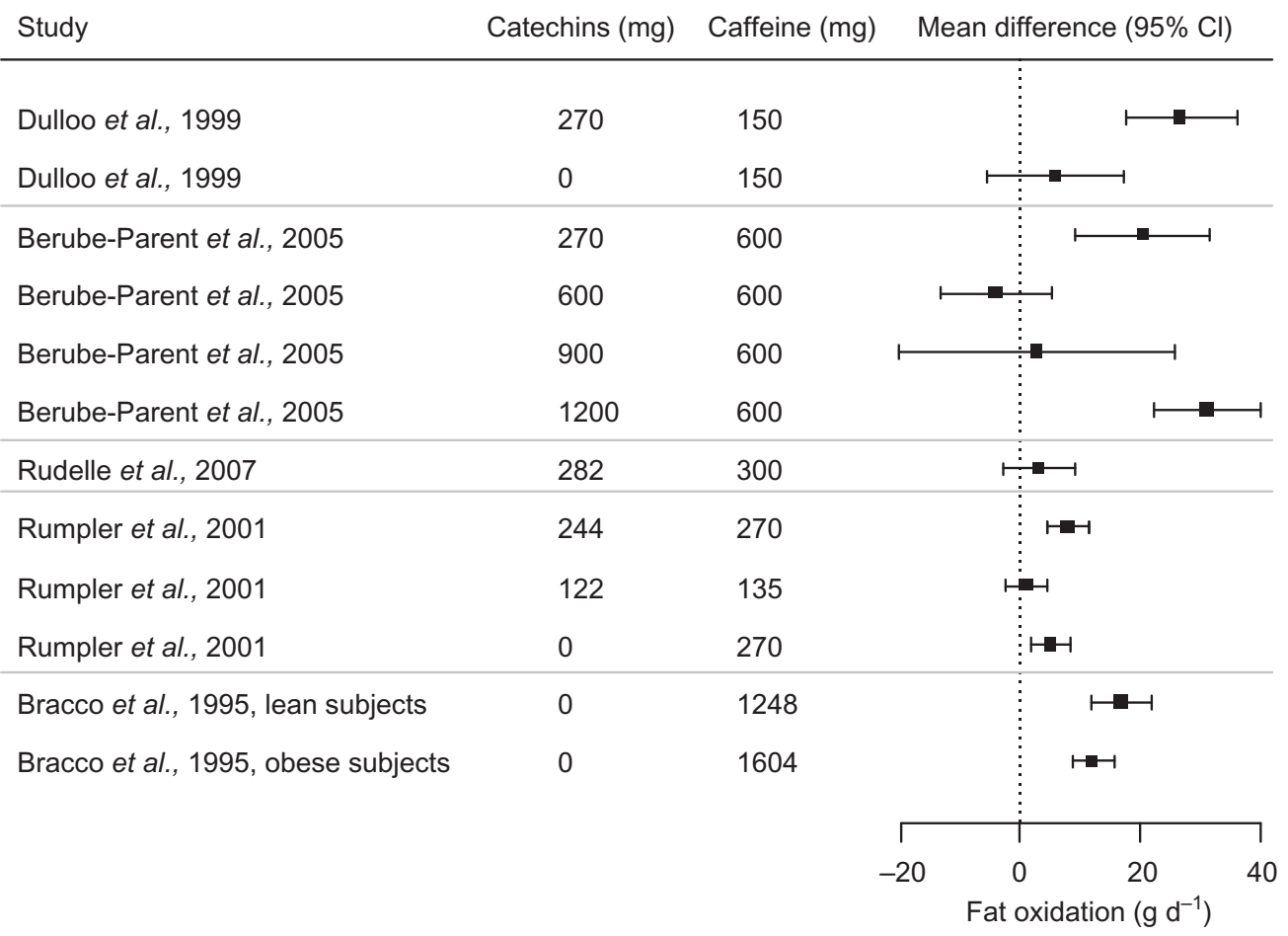

Figure 3 Plot of the mean differences (green/oolong tea or caffeine condition vs. placebo condition) with 95\% confidence intervals (Cl) for fat oxidation.

0.03, $P=0.01)$ and caffeine (0.01-point increase; $95 \% \mathrm{CI}$ : 0.00 to $0.02, P=0.02$ ).

\section{Discussion}

The results of this meta-analysis show that catechincaffeine mixtures and caffeine-only have a significant effect on energy expenditure. Moreover, compared with placebo, catechin-caffeine mixtures increased fat oxidation as well, in contrast to caffeine-only which did not yield a significant effect on fat oxidation. However, the overall result implies heterogeneity, most of which is accounted for by differentiating the three conditions.

Another moderator that might add some heterogeneity is BMI. Subjects with a higher BMI at baseline correspond to higher energy expenditure, although this is not the case for fat oxidation. Having a higher BMI and therefore higher energy expenditure is logical as heavier subjects have more fat-free mass, which is the main determinant of basal metabolic rate. An elevated sympathetic activity in the obese, which might explain the higher energy expenditure in obese subjects, has also been suggested in the past. However, there was doubt as studies reported both a diminished (30) and an increased (31) sympathetic activity in the obese state. Nowadays, it is accepted that there lies truth in both findings, as tissues have different magnitudes of sympathetic activity. For instance, the sympathetic nerve activity of muscle in obese subjects is over $50 \%$ higher compared with normal weight subjects, whereas the normal weight subjects have an increased cardiac sympathetic activity (32). For whole body sympathetic activity there does not seem to be a difference (32). In our study, BMI does not seem to influence the effects of catechin-caffeine mixtures and caffeine-only on energy expenditure and fat oxidation, suggesting that subjects with higher BMI may also benefit from sympathoadrenal stimulating ingredients.

A higher BMI at baseline did not correspond to increased fat oxidation after catechin-caffeine mixtures and caffeineonly supplementation. Usually subjects with an increased fat mass already have an increased fat oxidation over time as shown by Schutz et al. (33); however, Westerterp et al. (34) observed a reduction in percentage of post-prandial dietary fat oxidation in subjects with a higher percentage body fat. It is also known that fat oxidation does not abruptly increase in proportion to fat consumption (35). Hence, catechin-caffeine mixtures and caffeine-only might be expected to be less effective in increasing fat oxidation in subjects with high BMI as their absolute fat oxidation may already be at a high level. Furthermore, it is known that high intake of catechins can diminish dietary fat absorption (36-39), which might prevent storage of an adequate amount of fat and thereby resulting in less fat available for oxidation. The literature shows conflicting results with respect to the stimulatory effects of green tea on fat 
oxidation (20,21). A balance between fat absorption and fat oxidation might be one underlying cause as some individuals might respond through a decrease in fat absorption and others are more likely to enhance fat oxidation. However, until now such a balance has not been reported.

In our previous meta-analysis (19), ethnicity and regular caffeine intake contributed to the heterogeneity and acted as a moderator. The current meta-analysis could not take these moderators into account, as there were only Caucasian subjects involved in the included studies. Habitual caffeine intake was below $500 \mathrm{mg} \mathrm{d}^{-1}$ for each study, which is more than the $300 \mathrm{mg}$ that is normally used to discriminate between high and low habitual caffeine intakes. However, analyses were not conducted for the effect of habitual caffeine intake because most studies reported a range of caffeine intake above and below $300 \mathrm{mg}$ and not a specific threshold. Another moderator that might contribute to the variability of the results is composition or way of processing of the catechin-caffeine mixtures. Three out of four studies used an extraction while Rumpler et al. (28) used unfermented dry tealeaves to prepare a beverage. Further, catechin composition will most likely differ between studies with differences in, for instance, amounts of EGC, ECG and EC. Only in the study by Rumpler et al. (28) catechin composition was reported, the other studies only reported total catechin and EGCG content due to the use of patented extracts, which made an additional analysis, that could discriminate between effects of different catechins, impossible. Catechin composition differs strongly between teas, depending on features such as geographical location and environmental conditions like soil and temperature.

The inhibition of several enzymes may be the mechanism by which catechins and caffeine increase energy expenditure and fat oxidation, separately or synergistically in case of a catechin-caffeine mixture. Catechins inhibit COMT and caffeine inhibits phosphodiesterase (20). Levels of norepinephrine and cAMP rise because degradation by these enzymes is inhibited, thereby leading to increased thermogenesis and fat oxidation (20). Furthermore, after ingestion of catechins, hormone-sensitive lipase may be increased, which stimulates lipolysis (40) and will decrease acetyl CoA carboxylase that increases fat oxidation via malonyl CoA and carnitine palmitoyltransferase 1 (41). Fat metabolism may also be affected via other pathways by catechins: up-regulation of lipid-metabolizing enzymes via inhibition of nuclear factor-kappa B (42), decrease of fat absorption by inhibition of pancreatic and gastric lipases thereby probably attenuating fat emulsification (43) and finally, inhibition of the glucose transporters GLUT4 and SGLT1, thereby decreasing carbohydrate oxidation (44). Hence, catechins may activate multiple routes to stimulate fat oxidation in contrast to caffeine, which might explain why no significant effect was found on fat oxidation with caffeine-only in the current study.

Similar to the previous meta-analysis, it seems that there are also responders and non-responders to catechins and caffeine in short-term studies. Although, ethnicity could not be included in the current meta-analysis as a moderator because only studies with Caucasians studies fulfilled the inclusion criteria; differences in relevant enzyme activity, causing differences in sensitivity for these ingredients might explain why there are responders and non-responders. In that respect, Hodgson et al. stated that there is a wide variability in flavonoid O-methylation, a major pathway of flavonoid metabolism, by the enzyme COMT (45). The inter-individual variability of the activity of COMT could vary as much as threefold (45). Moreover, COMT enzyme activity differs between ethnic groups (46), in which Asian populations have a higher frequency of the thermostable, high-activity enzyme, COMT ${ }^{\mathrm{H}}$ allele (Val/Val polymorphism) than the Caucasian populations. The Caucasian populations have a higher frequency of the thermolabile, low-activity enzyme, COMT ${ }^{\mathrm{L}}$ allele (Met/Met polymorphism) (3). Fifty per cent of Caucasians are homozygous for the $\mathrm{COMT}^{\mathrm{L}}$ allele $(25 \%)$ and $\mathrm{COMT}^{\mathrm{H}}$ allele $(25 \%)$. The other $50 \%$ are heterozygous (Val/Met polymorphism) (46). This may explain the difference in sensitivity to interventions with catechin-caffeine mixtures, and why, in some studies with Caucasian subjects, no effect was seen after ingestion of a catechin-caffeine mixture. Furthermore, the previously discussed difference in catechin composition and way of processing might affect the qualitative and quantitative profiles of the catechins in tea consumed that will alter absorption and likely metabolism by COMT or other pathways such as glucuronidation and sulphation. Hence, the metabolism and ultimate 'activity' of the catechin mixture is likely influenced by tea composition as well.

The results of the meta-analysis also show that the difference in dosage between treatment and placebo had an effect on size of the effect. This finding is inconsistent with the results from the previous meta-analysis (19). This can be explained by the larger variation in dosage between the studies in the current meta-analysis. However, interesting is the fact that all studies supply their subjects with similar dosages, instead of administrating a subject-specific dosage per kg body weight, which might yield more unambiguous results. A dose-response effect on energy expenditure occurred with a mean increase of $0.53 \mathrm{~kJ} \mathrm{mg}^{-1}$ for catechins and $0.44 \mathrm{~kJ} \mathrm{mg}^{-1}$ for caffeine. While on average the effect of caffeine-only supplementation is not significantly different compared with placebo, there does appear to be a dose-response relationship on fat oxidation, with a mean increase of $0.02 \mathrm{~g} \mathrm{mg}^{-1}$ for catechins and $0.01 \mathrm{~g} \mathrm{mg}^{-1}$ for caffeine. To our knowledge, this is the first time that it has been determined in which proportion energy expenditure and fat oxidation increase with increasing dosage. 
However, given the limited precision of these estimates and the limited generalizability of the findings due to the small number of subjects, these results must be treated with caution.

Taken together, this meta-analysis shows that a catechincaffeine mixture and caffeine-only have a stimulating effect on energy expenditure. Furthermore, a catechin-caffeine mixture has also a stimulating effect on fat oxidation compared with placebo. Moreover, it also shows that people with increased BMI might benefit from the sympathoadrenal stimulating effect of a catechin-caffeine mixture while different doses of catechins have a significantly different effect. More research, especially focused on the balance between fat absorption and fat oxidation, genetic predisposition and catechin composition is needed to find out why the effects after catechin-caffeine mixture supplementation do not occur in all individuals.

\section{Conflict of interest statement}

None of the authors had a personal or financial conflict of interest.

\section{Acknowledgements}

$\mathrm{RH}$ and MSW-P designed the study. RH collected and prepared the data. WV analyzed the data. RH and WV wrote the manuscript and MSW-P contributed to the interpretation of the data and reviewed the manuscript. AGD, AT, LT and WR provided the data and reviewed the manuscript. The study was executed under the supervision of MSW-P.

\section{References}

1. Shixian Q, VanCrey B, Shi J, Kakuda Y, Jiang Y. Green tea extract thermogenesis-induced weight loss by epigallocatechin gallate inhibition of catechol-O-methyltransferase. J Med Food 2006; 9: 451-458.

2. Wolfram S, Wang Y, Thielecke F. Anti-obesity effects of green tea: from bedside to bench. Mol Nutr Food Res 2006; 50: 176-187.

3. Krul C, Luiten-Schuite A, Tenfelde A, van Ommen B, Verhagen $\mathrm{H}$, Havenaar R. Antimutagenic activity of green tea and black tea extracts studied in a dynamic in vitro gastrointestinal model. Mutat Res 2001; 474: 71-85.

4. Langley-Evans SC. Antioxidant potential of green and black tea determined using the ferric reducing power (FRAP) assay. Int J Food Sci Nutr 2000; 51: 181-188.

5. Serafini M, Ghiselli A, Ferro-Luzzi A. In vivo antioxidant effect of green and black tea in man. Eur J Clin Nutr 1996; 50: 28-32. 6. Westerterp-Plantenga M, Diepvens K, Joosen AM, BerubeParent S, Tremblay A. Metabolic effects of spices, teas, and caffeine. Physiol Behav 2006; 89: 85-91.

7. Diepvens K, Westerterp KR, Westerterp-Plantenga MS. Obesity and thermogenesis related to the consumption of caffeine, ephedrine, capsaicin, and green tea. Am J Physiol Regul Integr Comp Physiol 2007; 292: R77-R85.
8. Hsu CH, Tsai TH, Kao YH, Hwang KC, Tseng TY, Chou P. Effect of green tea extract on obese women: a randomized, doubleblind, placebo-controlled clinical trial. Clin Nutr 2008; 27: 363370 .

9. Nagao T, Hase T, Tokimitsu I. A green tea extract high in catechins reduces body fat and cardiovascular risks in humans. Obesity (Silver Spring) 2007; 15: 1473-1483.

10. Nagao T, Komine Y, Soga S, Meguro S, Hase T, Tanaka Y, Tokimitsu I. Ingestion of a tea rich in catechins leads to a reduction in body fat and malondialdehyde-modified LDL in men. Am J Clin Nutr 2005; 81: 122-129.

11. Auvichayapat P, Prapochanung M, Tunkamnerdthai O, Sripanidkulchai BO, Auvichayapat N, Thinkhamrop B, Kunhasura S, Wongpratoom S, Sinawat S, Hongprapas P. Effectiveness of green tea on weight reduction in obese Thais: a randomized, controlled trial. Physiol Behav 2008; 93: 486-491.

12. Hase T, Komine Y, Meguro S, Takeda Y, Takahashi H, Matsui Y, Inaoka S, Katsuragi Y, Tokimitsu I, Shimasaki H, Itakura $\mathrm{H}$. Anti-obesity effects of tea catechins in humans. J Oleo Sci 2001; 50: 599-605.

13. Kozuma K, Chikama A, Hishino E, Kataoka K, Mori K, Hase T, Katsuragi Y, Tokimitsu I, Nakamura H. Effect of intake of a beverage containing $540 \mathrm{mg}$ catechins on the body composition of obese women and men. Prog Med 2005; 25: 185-197.

14. Tsuchida $\mathrm{T}$, Itakura $\mathrm{H}$, Nakamura $\mathrm{H}$. Reduction of body fat in humans by long-term ingestion of catechins. Prog Med 2002; 22: 2189-2203.

15. Wang H, Wen Y, Du Y, Yan X, Guo H, Rycroft JA, Boon N, Kovacs EM, Mela DJ. Effects of catechin enriched green tea on body composition. Obesity (Silver Spring) 2009; e-pub ahead of print.

16. Diepvens K, Kovacs EM, Nijs IM, Vogels N, WesterterpPlantenga MS. Effect of green tea on resting energy expenditure and substrate oxidation during weight loss in overweight females. Br J Nutr 2005; 94: 1026-1034.

17. Kovacs EM, Lejeune MP, Nijs I, Westerterp-Plantenga MS. Effects of green tea on weight maintenance after body-weight loss. Br J Nutr 2004; 91: 431-437.

18. Westerterp-Plantenga MS, Lejeune MP, Kovacs EM. Body weight loss and weight maintenance in relation to habitual caffeine intake and green tea supplementation. Obes Res 2005; 13: 11951204.

19. Hursel R, Viechtbauer W, Westerterp-Plantenga MS. The effects of green tea on weight loss and weight maintenance: a meta-analysis. Int J Obes (Lond) 2009; 33: 956-961.

20. Dulloo AG, Duret C, Rohrer D, Girardier L, Mensi N, Fathi $\mathrm{M}$, Chantre P, Vandermander J. Efficacy of a green tea extract rich in catechin polyphenols and caffeine in increasing 24-h energy expenditure and fat oxidation in humans. Am J Clin Nutr 1999; 70: 1040-1045.

21. Berube-Parent S, Pelletier C, Dore J, Tremblay A. Effects of encapsulated green tea and Guarana extracts containing a mixture of epigallocatechin-3-gallate and caffeine on $24 \mathrm{~h}$ energy expenditure and fat oxidation in men. Br J Nutr 2005; 94: 432-436.

22. Boschmann M, Thielecke F. The effects of epigallocatechin-3gallate on thermogenesis and fat oxidation in obese men: a pilot study. J Am Coll Nutr 2007; 26: 389S-395S.

23. Gregersen NT, Bitz C, Krog-Mikkelsen I, Hels O, Kovacs EM, Rycroft JA, Frandsen E, Mela DJ, Astrup A. Effect of moderate intakes of different tea catechins and caffeine on acute measures of energy metabolism under sedentary conditions. Br J Nutr 2009; 102: 1187-1194.

24. Belza A, Toubro S, Astrup A. The effect of caffeine, green tea and tyrosine on thermogenesis and energy intake. Eur J Clin Nutr 2009; 63: 57-64. 
25. Viechtbauer W. Bias and efficiency of meta-analytic variance estimators in the random-effects model. J Educ Behav Stat 2005; 30: 261-293.

26. Bracco D, Ferrarra JM, Arnaud MJ, Jequier E, Schutz Y. Effects of caffeine on energy metabolism, heart rate, and methylxanthine metabolism in lean and obese women. Am J Physiol 1995; 269: E671-E678.

27. Rudelle S, Ferruzzi MG, Cristiani I, Moulin J, Mace K, Acheson KJ, Tappy L. Effect of a thermogenic beverage on 24-hour energy metabolism in humans. Obesity (Silver Spring) 2007; 15: 349-355.

28. Rumpler W, Seale J, Clevidence B, Judd J, Wiley E, Yamamoto S, Komatsu T, Sawaki T, Ishikura Y, Hosoda K. Oolong tea increases metabolic rate and fat oxidation in men. J Nutr 2001, 131: 2848-2852.

29. Dulloo AG, Geissler CA, Horton T, Collins A, Miller DS. Normal caffeine consumption: influence on thermogenesis and daily energy expenditure in lean and postobese human volunteers. Am J Clin Nutr 1989; 49: 44-50.

30. Bray GA. Obesity, a disorder of nutrient partitioning: the MONA LISA hypothesis. J Nutr 1991; 121: 1146-1162.

31. Landsberg L. Diet, obesity and hypertension: an hypothesis involving insulin, the sympathetic nervous system, and adaptive thermogenesis. Q J Med 1986; 61: 1081-1090.

32. Davy KP, Orr JS. Sympathetic nervous system behavior in human obesity. Neurosci Biobehav Rev 2009; 33: 116-124.

33. Schutz Y, Tremblay A, Weinsier RL, Nelson KM. Role of fat oxidation in the long-term stabilization of body weight in obese women. Am J Clin Nutr 1992; 55: 670-674.

34. Westerterp KR, Smeets A, Lejeune MP, Wouters-Adriaens MP, Westerterp-Plantenga MS. Dietary fat oxidation as a function of body fat. Am J Clin Nutr 2008; 87: 132-135.

35. Schutz Y, Flatt JP, Jequier E. Failure of dietary fat intake to promote fat oxidation: a factor favoring the development of obesity. Am J Clin Nutr 1989; 50: 307-314.

36. Raederstorff DG, Schlachter MF, Elste V, Weber P. Effect of EGCG on lipid absorption and plasma lipid levels in rats. I Nutr Biochem 2003; 14: 326-332.
37. Juhel C, Armand M, Pafumi Y, Rosier C, Vandermander J, Lairon D. Green tea extract (AR25) inhibits lipolysis of triglycerides in gastric and duodenal medium in vitro. J Nutr Biochem 2000; 11: 45-51.

38. Koo SI, Noh SK. Green tea as inhibitor of the intestinal absorption of lipids: potential mechanism for its lipid-lowering effect. J Nutr Biochem 2007; 18: 179-183.

39. Wang S, Noh SK, Koo SI. Epigallocatechin gallate and caffeine differentially inhibit the intestinal absorption of cholesterol and fat in ovariectomized rats. J Nutr 2006; 136: 2791-2796.

40. Acheson KJ, Gremaud G, Meirim I, Montigon F, Krebs Y, Fay LB, Gay LJ, Schneiter P, Schindler C, Tappy L. Metabolic effects of caffeine in humans: lipid oxidation or futile cycling? Am I Clin Nutr 2004; 79: 40-46.

41. Hursel R, Westerterp-Plantenga MS. Thermogenic ingredients and body weight regulation. Int J Obes (Lond) 2010; 34(4): 659_ 669.

42. Yang F, Oz HS, Barve S, de Villiers WJ, McClain CJ, Varilek GW. The green tea polyphenol (-)-epigallocatechin-3-gallate blocks nuclear factor-kappa B activation by inhibiting I kappa B kinase activity in the intestinal epithelial cell line IEC-6. Mol Pharmacol 2001; 60: 528-533.

43. Shishikura Y, Khokhar S, Murray BS. Effects of tea polyphenols on emulsification of olive oil in a small intestine model system. I Agric Food Chem 2006; 54: 1906-1913.

44. Kao YH, Hiipakka RA, Liao S. Modulation of endocrine systems and food intake by green tea epigallocatechin gallate. Endocrinology 2000; 141: 980-987.

45. Hodgson JM, Puddey IB, Burke V, Croft KD. Is reversal of endothelial dysfunction by tea related to flavonoid metabolism? $\mathrm{Br}$ J Nutr 2006; 95: 14-17.

46. Palmatier MA, Kang AM, Kidd KK. Global variation in the frequencies of functionally different catechol-O-methyltransferase alleles. Biol Psychiatry 1999; 46: 557-567. 